\title{
Abstract
}

This study adopts remote sensing techniques to compare the Surface urban Heat Island (SUHI) in Baghdad and London as they represent different climatic conditions, natural environments and levels of urban development. It tests the reported correlation of land surface temperature (LST) with land cover in the literature under different conditions and, based on the findings, suggests engineering mitigation strategies for each city. The land surface was characterized using supervised classification and spectral indices, using the Landsat 8 optical bands (2-7), and the LST was retrieved from Landsat's thermal band 10 after emissivity calibration. Two Landsat 8 satellite images were used, acquired in July 2013 when maximum surface temperature would be expected in both these capital cities. Image processing included radiometric calibration and atmospheric correction and various land surface indices were then calculated. The independent validation of land cover types was performed using higher spatial resolution optical data, and LST patterns were validated using ASTER thermal images. Land cover types or indices and land surface temperature display high correlations, with most having a positive relationship with LST, but vegetation has a negative relationship. The hottest surface type also differs for the two cities. Consequently, covering the soil in Baghdad with new construction, for example, reduces the surface temperature and hence urban heat island effect, while the same action in London increases it. Thus, engineering solutions to urban heat island issues need to take local factors into account.

Keywords: urban remote sensing, spatial change, surface urban heat island, land cover, spectral indices, mitigation strategies.

\section{1- Introduction}

Urban expansion is becoming a common concern worldwide as people leave rural areas and accumulate in major cities. Urban growth has economic benefits but also environmental consequences affecting climate change and global warming, leading to a direct impact on humans' lives [1]. The conversion of vegetation cover or bare soil to buildings and other impervious surfaces has altered the urban ecosystem, biodiversity and microclimate by triggering negative environmental phenomena such as urban heat islands (UHI) [1]. Remote sensing (RS) techniques can be used to determine the spatial change of the most important urban biophysical and environmental characteristics. The traditional way of evaluating the UHI is by measuring air temperature; nevertheless, recent studies employ remote sensing to determine radiated surface temperature [2]. Mirzaei and Haghighat [3] clarified that the resultant surface temperature contains the effects of surface radiative and thermodynamic properties, including surface moisture, surface emissivity, surface albedo, the irradiative input at the surface, and the effects of the near surface atmosphere, in addition to the turbulent transfer from the surface. The wide application of RS techniques in urban areas has included urban feature mapping based on their spectral signatures, as a time and cost effective approach compared to traditional methods such as field surveys [2]. They also provide quantitative observations about the environment in regions of the electromagnetic spectrum which are outside the visible region [4], such as temperature. Other techniques to study the UHI and simulate the urban climate are present in the literature such as Research and Forecasting (WRF) and ENVI-met. Morini, et al. [5] employed the WRF coupled to multi-layer urban canopy model (UCM) and building energy model (BEM) to study the impact of albedo increase to mitigate the UHI. Shen, et al. [6] used the ENVI-met to simulate urban climate parameters to evaluate the influence of microclimatic design on mitigating the UHI effects.

Oke et al. [7] explained that the surface temperature is not only important to study urban climatology, but it is central to the energy balance of the surfaces. Balling's study [8] is one of the earliest studies to apply thermal remote sensing to examine urban climates; this study concluded that the surface temperature is correlated with the land use and day to day variability of its spatial patterns. Beyond this, a study by Wang et al. [9] emphasised that surface 
temperatures and conductive heat fluxes through solid media (roofs, walls, roads and vegetated surfaces) are of major significance not only for microclimatic conditions outdoors but also for the comfort of residents indoors. Sobrino, et al. [10] have evaluated the SUHI influence in the city of Madrid by thermal remote sensing. They employed airborne hyperspectral data and in situ measurements, and the results demonstrated the presence of a night-time SUHI influence with a highest value of 5 K. A study by Rasul, et al. [11] employed six Landsat images to examine the spatial formation of the daytime Surface Urban Cool Island (SUCI) of the central districts of Erbil city in the north of Iraq. Their results indicated that the urbanised areas have lower LST acting as cool islands, compared to the rural area. Deng and Wu [12] have examined the impacts of urban biophysical compositions on SUHI using normalized difference vegetation index (NDVI), percent green vegetation $(\% \mathrm{GV})$, and percent impervious surface area (\%ISA). They used a spectral unmixing and thermal mixing approach; the result showed that NDVI and \%GVbased regression models perform well in rural areas, while \%ISA-based models perform well in urban areas. Furthermore, the influence of temporal aggregation of LST data for SUHI has been studied by Hu and Brunsell [13]. Their study found that the SUHI values in the daytime are larger than during the night-time, and the impacts of aggregation in spring and summer are higher than in autumn and winter. Hadjimitsis, et al. [14] have used satellite Earth observation data and ground meteorological data to study the effect of SUHI in Cyprus using Artificial Neural networks (ANN). Their findings have revealed that the approach can perform successfully as good correlations between ground and satellite measurements were identified. However, further modification is needed in order to improve this methodology due to the course $1 \mathrm{~km}$ resolution of MODIS LST data.

To counterbalance the influence of the UHI, there are two main mitigation strategies as described by Akbari and Kolokotsa [15]. The first strategy is increasing the solar reflectance, to reduce the amount of solar radiation absorbed by the urban fabric. It uses high reflectance and high thermal emittance materials, these materials decrease the LST by using them in the building's walls, roofs and pavements [15]. Morini, et al. [5] investigated the impact of albedo increase to countermeasure the UHI and its negative consequences in Terni (Italy) by using the Weather Research and Forecasting (WRF). Their findings after analysing three different scenarios of a summer heat wave in 2015 showed that albedo increase can mitigate the peak temperatures of the daytime by $1{ }^{\circ} \mathrm{C}$ and night-time by up to $2{ }^{\circ} \mathrm{C}$. Furthermore, Rossi, et al. [16] identified the beneficial effects of using retro-reflective (RR) materials in urban canyons to reduce the impact of UHI. They tested the application of a new RR material, which is a high reflective material that should reflect the incident radiation backward to the same direction of incidence. The results suggested that RR materials can improve the summer urban climate through providing cooling potential as coatings in urban canyons. On the other hand, the second strategy to minimise the UHI effects is increasing the evapotranspiration by intensifying the urban greenery such as parks and green roofs [15]. For example, a study by Jim [17] assessed the use of green roofs on thermal comfort in Hong Kong by developing a full scale experiment in a high rise building. The study concluded that the green roof with high rate of evapotranspiration can mitigate the UHI impact by reducing the foliage surface temperature and surrounding air. The effects of UHI can lead to detrimental consequences of the indoor and outdoor public and private spaces. The outdoor thermal natural and built environment are important particularly in public spaces during outdoor events, and they contribute to improve the quality of life [18]. Rossi, et al. [18] proposed an integrated approach to improve the global comfort condition during outdoor entertainment events in summer. Their system suggested the use of proper architectural solutions and materials to enhance the outdoor environment.

This paper adopts some of these remote sensing techniques to investigate the formation of areas of high and low temperatures known as the heat island phenomenon. Landsat has been a source of data for different disciplines such 
urban mapping and environmental monitoring, for over four decades [19]. It provides the longest constantly acquired collection of space born remotely sensed data. So it is used in this study to investigate the difference in the spatial variation in temperature for different environments. The Landsat 8 satellite [20] began normal operations on May 30, 2013; it carries two sensors, the Operational Land Imager (OLI) and a Thermal Infrared Sensor (TIRS). This study employs both sensors to investigate the relationship between different land cover types and the land surface temperature (LST). LST is a strong indicator of one component of the urban heat island phenomenon [21], known as the surface urban heat island (SUHI), which is based on surface temperatures as opposed to air temperatures. The aims of this paper are to investigate and compare the SUHI in Baghdad and London as they represent different climatic conditions, natural environments and levels of urban development; to test the reported correlation with land cover under such different conditions; and based on the findings; suggest engineering mitigation strategies for each city. So, this paper tests the impact of irreversible urban expansion on UHI, which naturally leads to land cover changes, and how this correlates with the applications of UHI mitigation techniques. To do this, land cover classification, LST retrieval and spectral indices will be derived and validated using independent datasets, as detailed in the next section.

\section{2- Methodology}

\section{A. Study sites}

Baghdad and London have been chosen as the study sites because they have different geographical locations, climatic conditions, land cover patterns, and consequently the potential to demonstrate spatial variation in LST. Furthermore, London is the capital of a developed country (UK) that has practiced UHI mitigation strategies [22], whereas, Baghdad is the capital of a developing country (Iraq) where UHI studies have not received much attention [23]. In 2011, Baghdad had a population of 7,055,200 and covered $734 \mathrm{Km}^{2}$ [24] and London had a similar population of $8,173,941$ but covered $1,572.00 \mathrm{~km}^{2}$. So, compared with Baghdad, London has higher population by around one million people, while its population density is much lower, its area being approximately twice that of Baghdad. Baghdad's climate is subtropical arid with hot summers and cold winters, while London's climate is temperate oceanic with warm summers and mild winters [24].

\section{B. Data and Method}

Image processing has been undertaken that aims to evaluate the spatial change of land temperature due to different land covers. The process included the conversion of Landsat 8 image digital numbers to reflectance values for the visible to shortwave infrared bands (bands 2-7). Then, the brightness temperature was calibrated using the thermal band (band 10). The process also removed the atmospheric effects, using the dark object subtraction algorithm to correct all the bands within QGIS software. QGIS is an open source software that can be downloaded free of charge from the QGIS website [25]. The land cover types were classified using training classes validated using a high spatial resolution Basemap in ArcGIS 10.2. After that, emissivity values for different classified land covers were assigned from a lookup table to derive the land surface temperature based on a single channel method [26]. Spectral indices were derived from the reflectance values as indicators for the various land cover types. Then, the relationships between land surface temperature and land cover were investigated using ArcGIS and Excel. This hypothesis being tested is the assumption in the literature reviewed in the previous section that, neglecting other possible influencing parameters, the change of LST is mainly due to land cover types. 
Two images have been employed acquired on the $10^{\text {th }}$ of July 2013 at 07:35 GMT (local time +3 hours) for Baghdad and on the $17^{\text {th }}$ at 10:54 GMT (local time +1 hour) for London, all downloaded from the USGS website [27]. The derived spectral indices are enhanced built-up and bareness index (EBBI), normalized difference bareness index (NDBaI), normalized difference built-up index (NDBI), urban index (UI), normalized difference water index (NDWI), and normalized difference vegetation index (NDVI). Each index is high for the specified land cover and low for other surfaces; more details can be found in [28], [29] and [30]. However, the indices available in the literature were derived for Landsat 4, 5 and 7, so they have been modified for this study Landsat 8 as shown below.

$$
\begin{gathered}
E B B I=\frac{b_{6}-b_{5}}{\sqrt[10]{b_{6}+b_{10}}} \\
N D B a I=\frac{b_{6-}-b_{10}}{b_{6}+b_{10}} \\
N D B I=\frac{b_{6-b_{5}}}{b_{6}+b_{5}} \\
U I=\frac{b_{7}-b_{5}}{b_{7}+b_{5}} \\
N D W I=\frac{b_{8-}-b_{5}}{b_{5}+b_{5}} \\
N D V I=\frac{b_{5-b_{4}}}{b_{5}+b_{4}}
\end{gathered}
$$

Where $b_{3}$ and $b_{4}=$ visible green and red, $b_{5}=$ near infrared, $b_{6}$ and $b_{7}=$ shortwave infrared, and $b_{10}=$ thermal infrared.

In order to validate the land surface temperature patterns using different sets of images, two ASTER images were also acquired from GLOVIS (Global Visualization Viewer) [31]. These images were rescaled using the parameter available in the product description (AST_08) and converted to Celsius as they are made available in kelvin. The comparison between Landsat 8 and ASTER thermal bands is viable as they both cover the spectral range between 8 and $12 \mu \mathrm{m}$. Also, the spatial resolution of acquisition is very similar at 90m for ASTER and 100m for Landsat8; however, Landsat 8 thermal bands are resampled to $30 \mathrm{~m}$ to match other bands. The ASTER images used were acquired the on the $19^{\text {th }}$ of February 2011 at 07:50 (GMT) for Baghdad, and $26^{\text {th }}$ of May 2012 at 11:15 (GMT) for London, so that the acquisition time of ASTER and Landsat 8 images is almost the same. Although the ASTER images are not from the same year as the Landsat 8 images, due to the challenge of getting free cloud images and the difference in the swath width between the two satellites, nevertheless, the time interval between the images is not large enough to cause a significant spatial variability of land cover types. Khan and Powell [32] highlighted that it is reasonable to only develop comprehensive land use accounts every few years., as land area does not change significantly over a short period of time. Accordingly, it has been assumed that similar temperature patterns will occur at the equivalent time of year for the same land cover types.

\section{3- Results and discussion}

\section{1- LST and classified land cover types}

The classification of land cover types for Baghdad and London is illustrated in Fig.1 and Fig.2. The maximum likelihood classifier performed better than other algorithms, and it was validated using existing studies in the literature that classified land cover types in both cities. 


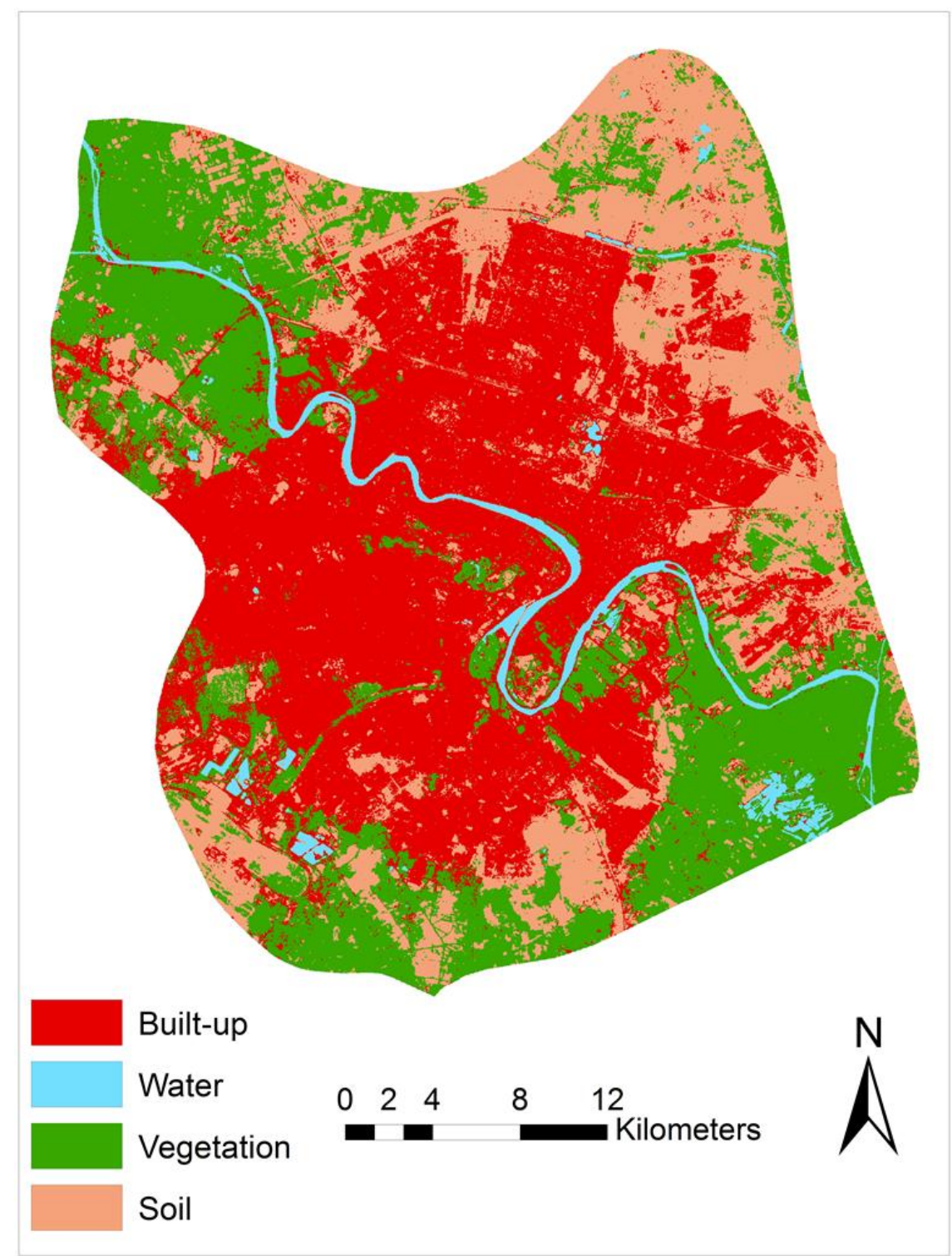

Fig.1 Classification of Baghdad's land cover based on Landsat 8 data 


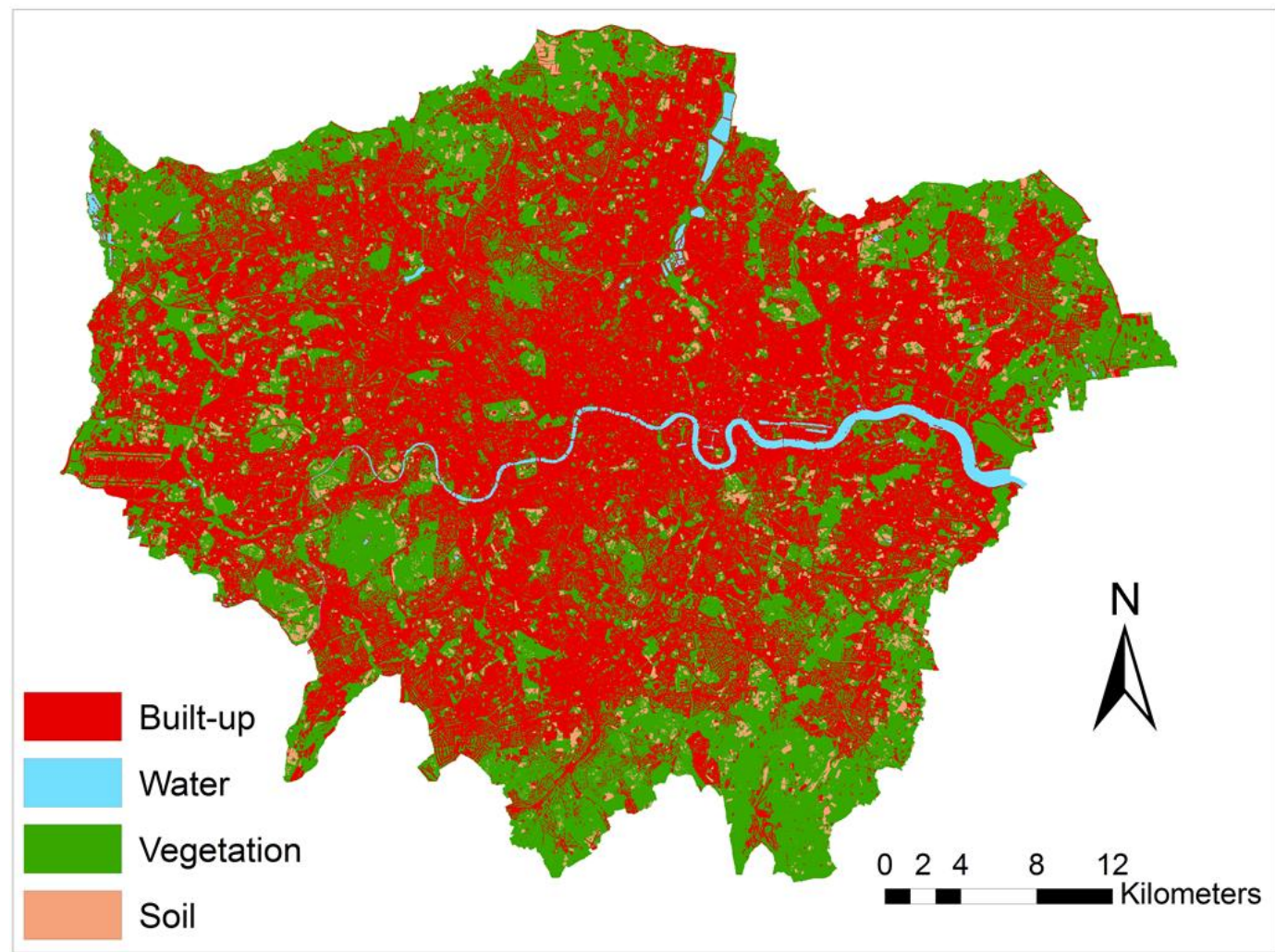

Fig. 2 Classification of London's land cover based on Landsat 8 data

The classified land covers are vegetation, water and soil and built-up and, as clarified in Table 1, they show distinct differences in percentage covers between Baghdad and London. It could be seen that the impervious surface (built-up area) in Baghdad is $43.62 \%$, while, in London it forms $56.37 \%$ of the total. Moreover, vegetated areas in Baghdad appear more in rural areas than urban fabric and form $28.15 \%$ of the total, whereas, the $37.87 \%$ of London's vegetated areas has a good percentage cover within urban areas. However, soil lands in Baghdad cover around $25.30 \%$ of the entire area, while in London this figure is just $4.24 \%$. Even though the four main classes identified do not describe all the variety of land covers that occur in both cities, they do show the main overall components in both environments. The assessment of land cover classification showed good accuracy in comparison to existing results from studies [23] and [33] after summing their classes under the four main categories to be compared within this study. A further accuracy assessment was done using a confusion matrix and the kappa values for Baghdad and London are 83.4 and 81.2 respectively. However, this figure should be viewed with caution, as the data used has a $30 \mathrm{~m}$ pixel resolution in which mixed pixels will be common.

Table 1 Percentages of classified areas in Baghdad and London

\begin{tabular}{|c|c|c|}
\hline Cover\City & Baghdad\% & London\% \\
\hline Built-up & 43.62 & 56.37 \\
\hline Vegetation & 28.15 & 37.87 \\
\hline Soil & 25.30 & 4.28 \\
\hline Water & 2.93 & 1.48 \\
\hline
\end{tabular}

The LST patterns display interesting differences in behavior between London and Baghdad. The distribution of hot spots in London extends over the whole city, unlike Baghdad, where the hot spots are more concentrated towards the north east. These patterns reflect the distribution of the hottest land-cover types in each case. London's 
built-up surfaces recorded the highest temperature and are widely distributed, and then the soil and vegetation had lower temperatures. In contrast, Baghdad's soil areas had the highest temperature and are concentrated in the north east of the city, and then built up and vegetation areas had lower temperatures. Both cities had the lowest temperature for water (see Fig.3 and Fig.4). Each land cover type reflects a certain class of LST interval, and in this case the relationship is obvious between the dependent and independent parameters. The identification of LST patterns using land cover types thus appears to be a feasible approach to investigate the spatial variation of SUHI using only visual interpretation.

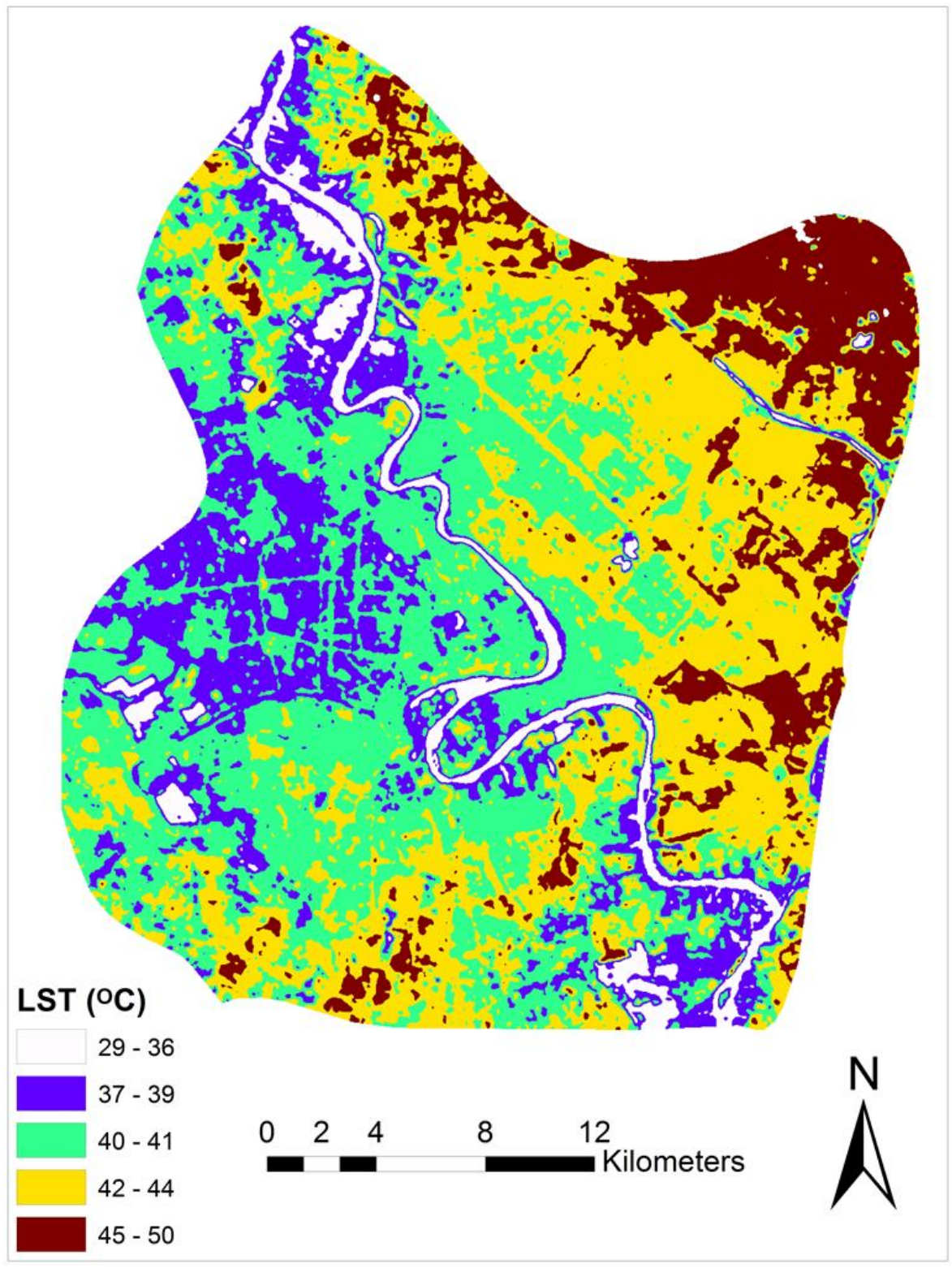

Fig. 3 Baghdad's land surface temperature from Landsat 8 data 


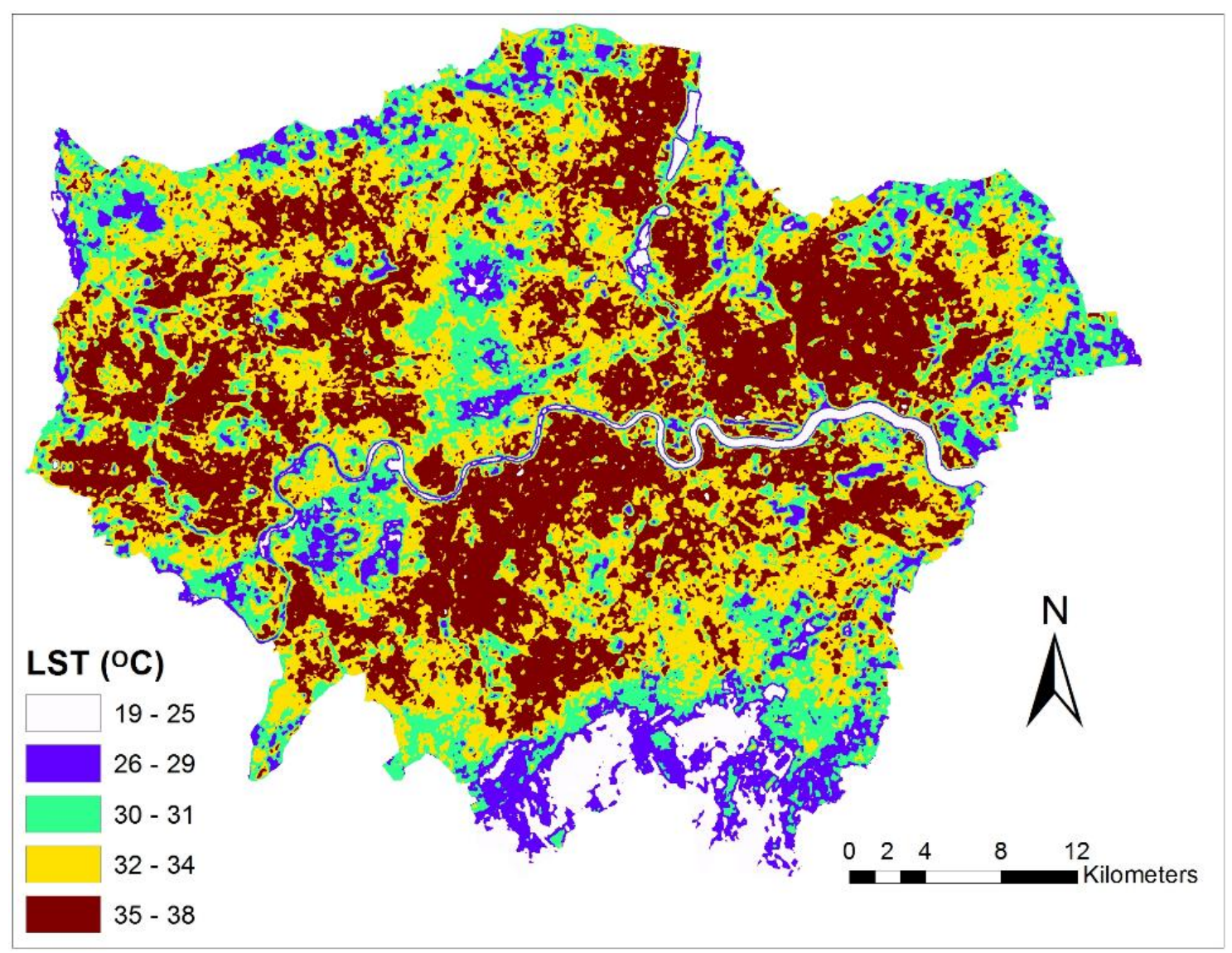

Fig. 4 London's land surface temperature from Landsat 8 data

\section{2- LST and spectral indices}

In order to go beyond visual interpretation, the relationships between LST and various land surface indices were investigated and seem to be consistent for most indices in both cities (see Fig.5 and Fig.6). As-syakur, et al. [28] clarified that EBBI is able to capture and distinguish built-up and bare land areas, and it was proposed because NDBI and UI are unable to verify the distribution of built-up versus bare land areas. Similarly, Bouhennache, et al. [34] stated that the urban and soil features are more distinguishable in UI rather than NDBI. Furthermore, high NDVI values indicate the presence of vegetation, which results in low values of EBBI, NDBaI, NDBI, and UI [28]. Ogashawara and Bastos [35] highlighted the importance of the NDWI index to enhance the detection of water content within vegetation, and it is less sensitive to atmospheric scattering effects compared with the NDVI. Ogashawara and Bastos [35] found that urban and bare areas correlated positively with high temperatures, whereas, vegetation and water correlated positively with low temperatures. Fig.5 and Fig.6 show that EBBI, NDBaI, NDBI, NDWI and UI have positive relationships with LST and NDVI has a negative relationship. These results agree with existing studies [29] and [30] for all the indices except NDWI, which usually has negative relationship with LST. Fig.5 gives the correlations between LST and land cover indices for Baghdad, which positive for most indices except NDVI. The $\mathrm{R}^{2}$ fluctuates significantly from over 0.4 for EBBI, NDBaI, NDBI and UI to about zero for NDWI. For London, the correlations between LST and land cover indices are mostly positive except for NDVI, just similar to Baghdad, as shown in Fig.6. The $\mathrm{R}^{2}$ reaches over 0.4 for EBBI and NDBI, and it is lower than 0.2 for NDBaI, UI, NDWI and NDVI (see Fig.6). The weak positive correlation between LST and NDWI maybe due to the derived index NDWI being adapted to use the green and near infrared bands. Nevertheless, a recent study by Du et al. [36] highlights that using the green $\left(b_{3}\right)$ and shortwave $\left(b_{6}\right)$ bands for Landsat8 will give higher accuracy for surface water mapping and so this adaptations is reasonable. Moreover, whilst EBBI, NDBI and UI indices have 
high correlation with LST, there is lower correlation with NDBaI, NDWI and NDVI for both cities. This lower correlation maybe explained by considering key difference between the spectral indices and the classification of land cover types, spectral indices do not reflect a certain percentage of land cover but, rather the dominant presence of a particular feature by pixel compared to others. For example, London does not have large barren areas; however, even for areas of other land-cover types, such as built-up areas, the barren index can be derived. Furthermore, although Baghdad has much larger barren areas than London, for example, the correlation between LST and NDBaI is low for both cities. In other words, spectral indices are useful to determine the correlations with LST for sparse pixels of the same land cover type, but the classification of land cover types is more useful when investigating specific land cover type concentrated in one region.
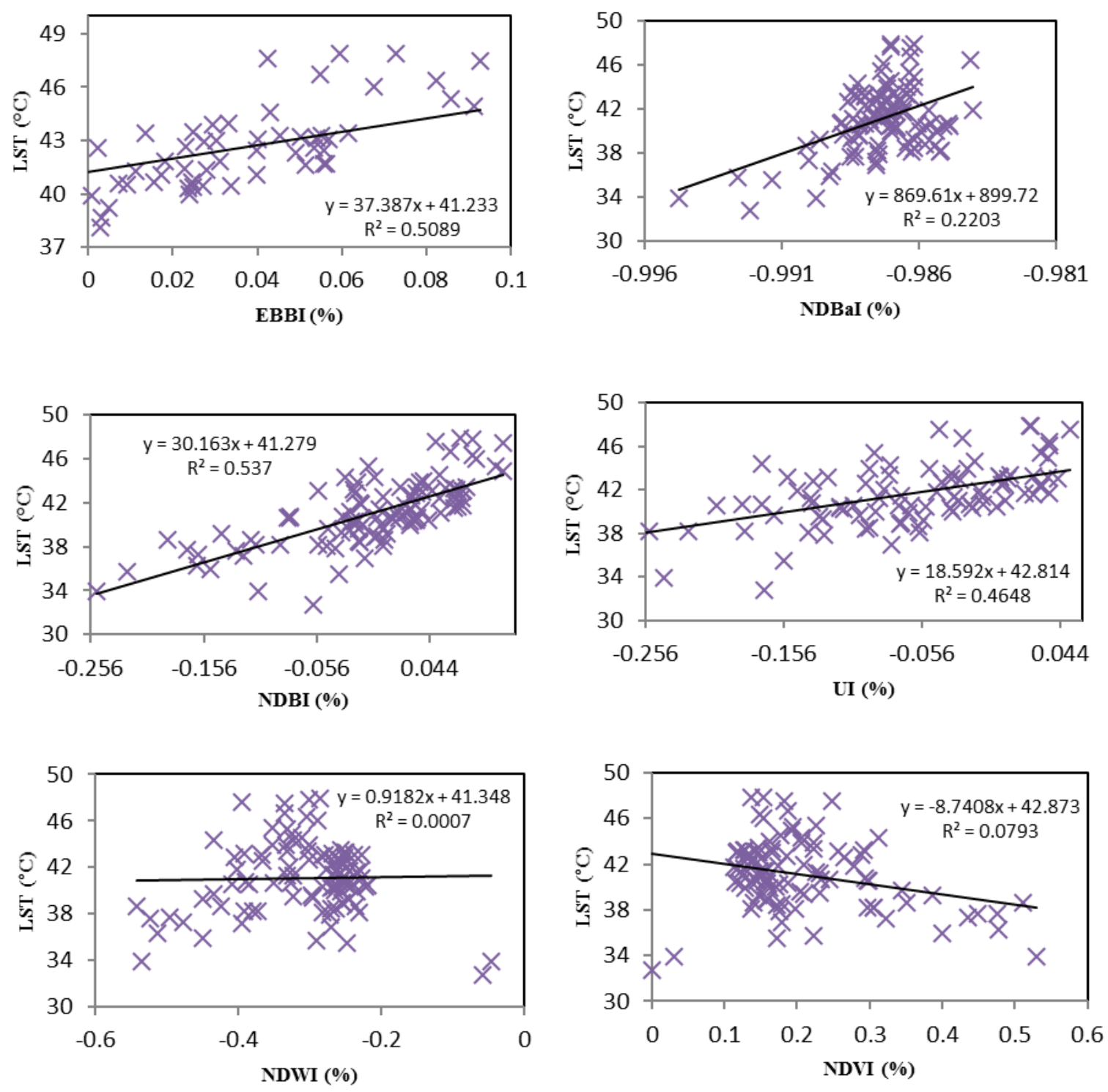

Fig. 5 Land surface temperature and land cover indices relationships of Baghdad 

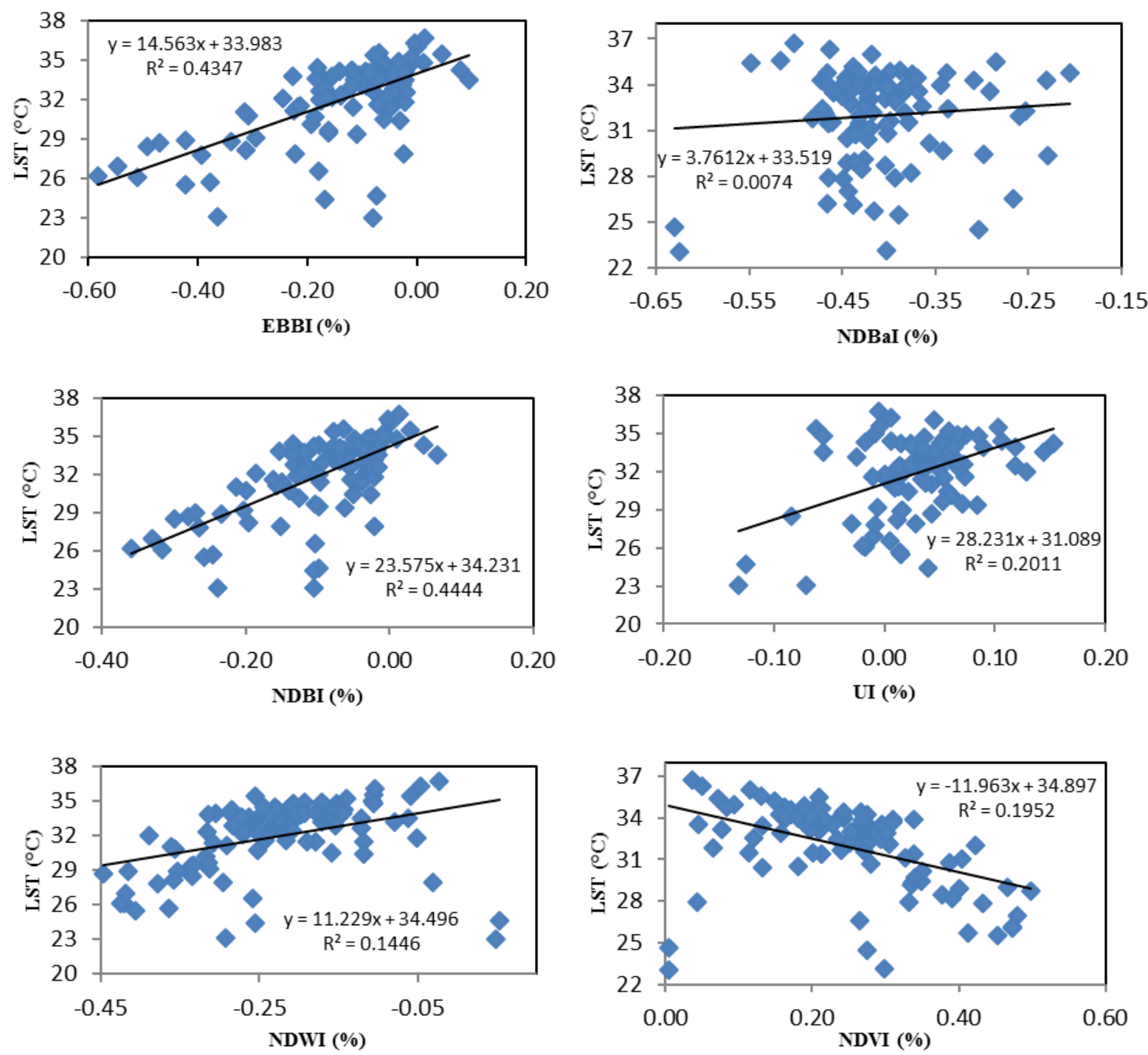

Fig. 6 Land surface temperature and land cover indices relationships of London

\section{3- Validation of LST patterns}

The validation of temperature spatial patterns derived from Landsat 8 using ASTER images shows exactly the same behavior for different land covers as shown in Fig.7 and Fig.8. It can be seen that the urban areas for London recorded the highest temperature; on the contrary, soil cover had the highest temperature levels in Baghdad. From that, the feasibility of comparing different environments using remote sensing images can be appreciated. Nevertheless, whilst the distribution of LST patterns in Baghdad from the ASTER image is concentrated close to its boundary compared to Landsat 8 image, the overall behavior is still the same. As a result, the reflected and emitted energy from the earth surface remains distinctive and consistent for specific land covers after the radiometric and atmospheric correction [37]. Although, the ASTER images used were not acquired in the same season as the Landsat images, the spatial distribution of SUHI looks similar; this highlights the distinctive impact of land cover types on SUHI regardless of the climatic conditions. Further support for this conclusion is provided by two independent studies: a study was done on Basarah City in the south of Iraq, which reported that dry and wet soil have the highest temperature among all other land covers [38]; likewise, a report published by The Greater London Authority found that the association between high surface temperatures and developed areas (or built-up) across London is clearly evident [22]. 


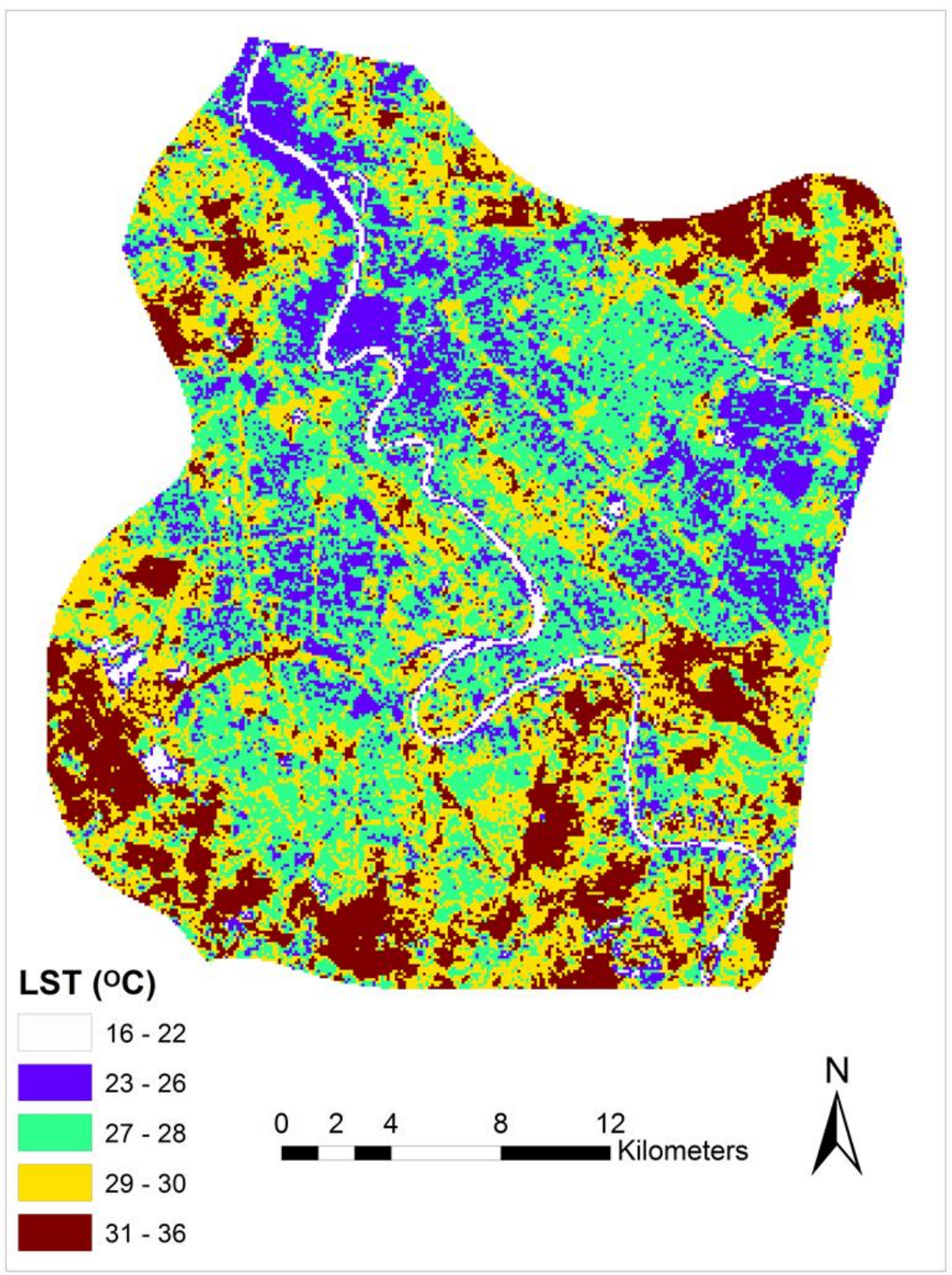

Fig. 7 Baghdad's land surface temperature using ASTER 


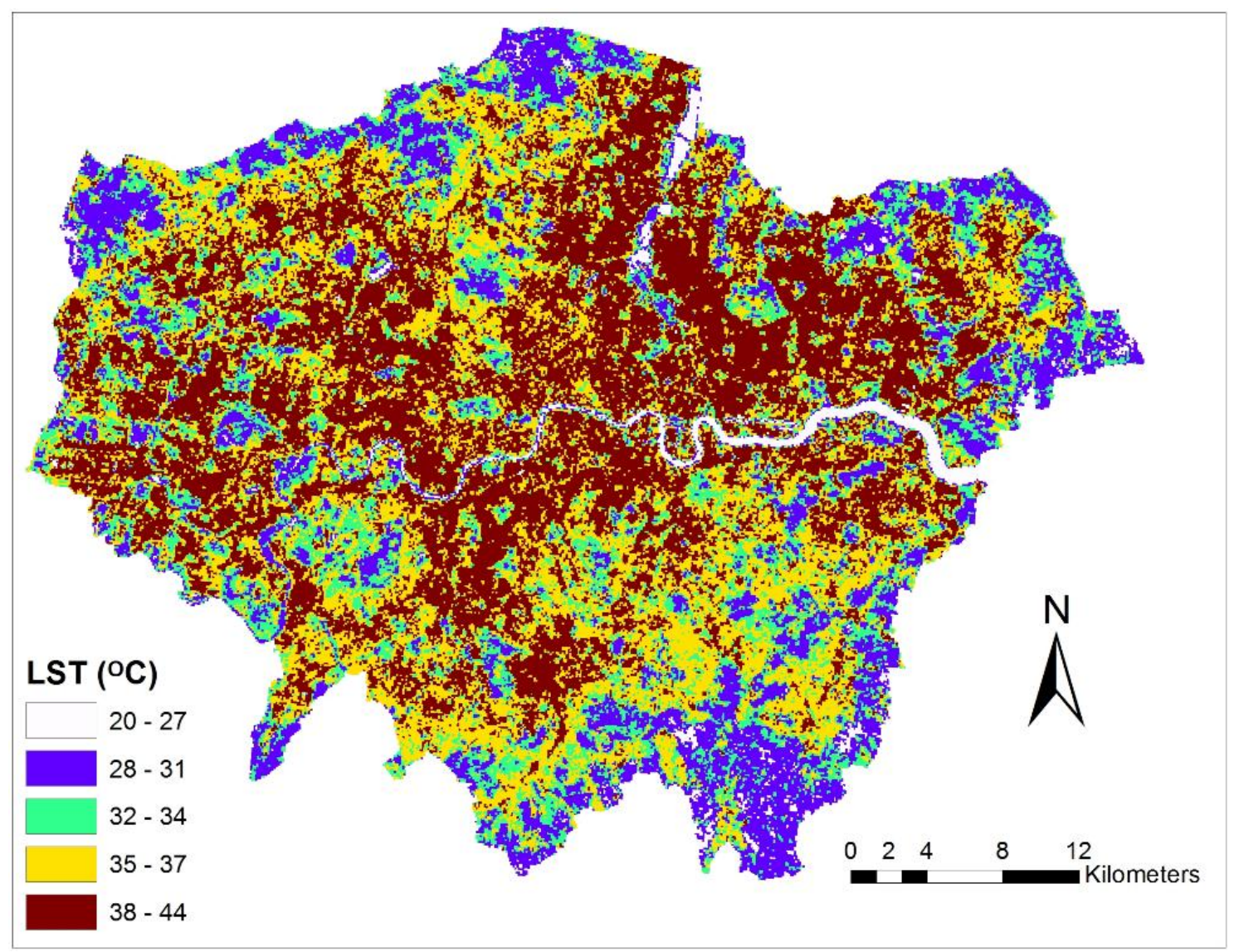

Fig. 8 London's land surface temperature using ASTER

\section{4- Mitigation strategies}

The findings of this study reveal that a number of mitigation measures can be adopted in London and Baghdad to relieve the impact of SUHI. The LST in London was at the maximum for the built up areas, so the horizontal urban expansion will increase the coverage of hot spots (as shown in Fig.4 \& Fig.8). This expansion reduces the evapotranspiration process and increases the urban traps of solar radiations by replacing the vegetated areas that are dominant along the city boundary by impervious surfaces. Accordingly, vertical expansion is advised in London to keep the green surfaces and, to minimise the SUHI effect, more vegetation should be planted. The greenery does not have to be on the ground as green roofs and walls can reduce the heat stress and improve the air quality in the city without exploiting more lands. Alternative solutions where the vertical expansion is not possible can be using RR materials, because these materials reflect the radiation towards the same incoming direction as described by Rossi, et al. [39] and Rossi, et al. [16]. In Baghdad, the plan to mitigate the SUHI should differ, as the spatial distribution of the hot areas contradicts London's condition.

It is evident from Fig.3 and Fig.7 that the highest LST areas in Baghdad lie close to the boundary of the city in bare soil, in contrast to London. Therefore, horizontal expansion will cover the hot soil and change that to cooler built-up or vegetated areas. Furthermore, the use of cool materials for walls, roofs and pavements (as described earlier) for the newly developed areas would minimise the UHI formation. And for the outdoor public environments, the use of proper architectural solutions and materials would enhance the acoustic, lighting and thermal comfort condition especially for outdoor events as detailed by Rossi, et al. [18]. In this case the urbanisation impact on the SUHI will be positive when it coincides with more vegetated areas in houses' backyard or parks as well as using cool materials. Two major differences are responsible for opposite mitigations strategies being appropriate for 
Baghdad and London; their contrasting levels of development and regional climates. For example of contrasting levels of development, is that Baghdad does have many green areas in the city centre as London, and even in the rural areas Baghdad does have much natural vegetation except the agriculture due to dry weather which reflects the lack of UHI mitigation countermeasures for Baghdad compared to London. Accordingly, it can be seen that in terms of impact on a city's SUHI, urban expansion is not always negative. Different environments might need opposite mitigation actions and the policy makers, planners, climatologists, and engineers working on this problem must take this into account.

\section{5- Conclusions and future work}

The classification of urban land covers using Landsat 8 gives a good estimate of the main urban feature classes which are built-up, vegetation, water and soil. However, for more detailed classification of urban materials higher spectral and spatial resolution remote sensing data is needed. The use of spectral indices is an effective alternative for classification to be used as indicators for different urban land covers. The thermal bands of Landsat 8 capture the spatial variability of LST patterns for both cities well and this was validated using ASTER thermal images. The relationships between LST and most of the derived spectral indices were positives except for NDVI. Furthermore, various land cover classes have different impacts on surface temperature in different environments. Converting bare (soil) lands to built-up surface elevates the temperature in a wet city like London, whereas in a dry city such as Baghdad it reduces the LST. From this outcome, the horizontal expansion for a city in a dry environment such as Baghdad is advised, with built-up and vegetated surfaces being cooler than the barren land that they replace. In contrast, for a wet environment with a considerable amount of vegetation the vertical urban expansion will be more appropriate to prevent hotter built-up surfaces replacing cooler vegetation and soils. Alternative solutions to reduce the LST of the built-up areas can be using cool materials such as RR materials through their high reflectance in the same direction of the incidence radiation. The low correlation between LST and some of the spectral indices reflects that there are other influencing parameters on LST, as well as land cover types. So, future work will investigate these other influencing parameters on LST, such as meteorological conditions, surface energy parameters, and geometrical factors.

\section{Acknowledgements}

The study was funded by the Iraqi government through its cultural attaché in London. The authors would like to thank the U.S. Department of the Interior, United States Geological Survey for providing the Landsat data free of charge. Another special thanks to the USGS Earth Resources Observation and Science (EROS) Data Center, who provided the ASTER data on the same basis.

\section{References}

[1] H. Xu, F. Ding, and X. Wen, "Urban expansion and heat island dynamics in the Quanzhou Region, China," IEEE Journal of Selected Topics in Applied Earth Observations and Remote Sensing, vol. 2, pp. 74-79, 2009.

[2] Q. Weng, "Remote sensing of impervious surfaces in the urban areas: Requirements, methods, and trends," Remote Sensing of Environment, vol. 117, pp. 34-49, 2/15/ 2012.

[3] P. A. Mirzaei and F. Haghighat, "Approaches to study Urban Heat Island - Abilities and limitations," Building and Environment, vol. 45, pp. 2192-2201, 10// 2010.

[4] E. Chuvieco and A. Huete, Fundamentals of satellite remote sensing / Emilio Chuvieco and Alfredo Huete: CRC, 2010.

[5] E. Morini, A. G. Touchaei, B. Castellani, F. Rossi, and F. Cotana, "The Impact of Albedo Increase to Mitigate the Urban Heat Island in Terni (Italy) Using the WRF Model," Sustainability, vol. 8, p. 999, 2016. 
[6] T. Shen, D. Chow, and J. Darkwa, "Simulating the influence of microclimatic design on mitigating the Urban Heat Island effect in the Hangzhou Metropolitan Area of China," International Journal of Low-Carbon Technologies, p. ctt050, 2013.

[7] T. R. Oke, R. A. Spronken-Smith, E. Jáuregui, and C. S. B. Grimmond, "The energy balance of central Mexico City during the dry season," Atmospheric Environment, vol. 33, pp. 3919-3930, 10// 1999.

[8] R. B. Balling, SW, "High-resolution surface-temperature patterns in a complex urban terrain," Photographic Engineering Remote Sensing, vol. 54, pp. 1289-1293, 1988.

[9] Z.-H. Wang, E. Bou-Zeid, and J. Smith, "A Spatially-Analytical Scheme for Surface Temperatures and Conductive Heat Fluxes in Urban Canopy Models," Boundary-Layer Meteorology, vol. 138, pp. 171-193, 2011/02/01 2011.

[10] J. A. Sobrino, R. Oltra-Carrió, G. Sòria, J. C. Jiménez-Muñoz, B. Franch, V. Hidalgo, et al., "Evaluation of the surface urban heat island effect in the city of Madrid by thermal remote sensing," International journal of remote sensing, vol. 34, pp. 3177-3192, 2013.

[11] A. Rasul, H. Balzter, and C. Smith, "Spatial variation of the daytime Surface Urban Cool Island during the dry season in Erbil, Iraqi Kurdistan, from Landsat 8," Urban Climate, vol. 14, Part 2, pp. 176-186, 12// 2015.

[12] C. Deng and C. Wu, "Examining the impacts of urban biophysical compositions on surface urban heat island: A spectral unmixing and thermal mixing approach," Remote Sensing of Environment, vol. 131, pp. 262-274, 4/15/ 2013.

[13] L. Hu and N. A. Brunsell, "The impact of temporal aggregation of land surface temperature data for surface urban heat island (SUHI) monitoring," Remote Sensing of Environment, vol. 134, pp. 162-174, 7// 2013.

[14] D. G. Hadjimitsis, A. Retalis, S. Michaelides, F. Tymvios, D. Paronis, K. Themistocleous, et al., Satellite and Ground Measurements for Studying the Urban Heat Island Effect in Cyprus, 2013.

[15] H. Akbari and D. Kolokotsa, "Three decades of urban heat islands and mitigation technologies research," Energy and Buildings, vol. 133, pp. 834-842, 2016.

[16] F. Rossi, E. Morini, B. Castellani, A. Nicolini, E. Bonamente, E. Anderini, et al., "Beneficial effects of retroreflective materials in urban canyons: results from seasonal monitoring campaign," in Journal of Physics: Conference Series, 2015, p. 012012.

[17] C. Jim, "Assessing climate-adaptation effect of extensive tropical green roofs in cities," Landscape and Urban Planning, vol. 138, pp. 54-70, 2015.

[18] F. Rossi, E. Anderini, B. Castellani, A. Nicolini, and E. Morini, "Integrated improvement of occupants' comfort in urban areas during outdoor events," Building and Environment, vol. 93, pp. 285-292, 2015.

[19] USGS. (2013, 1June ). Landsat Project Description. Available: http://landsat.usgs.gov/about_project_descriptions.php

[20] D. P. Roy, M. A. Wulder, T. R. Loveland, W. C.E, R. G. Allen, M. C. Anderson, et al., "Landsat-8: Science and product vision for terrestrial global change research," Remote Sensing of Environment, vol. 145, pp. 154-172, 4/5/ 2014.

[21] EPA. (2008, 1 June 2014). Reducing Urban Heat Islands: Compendium of Strategies. Available: http://www.epa.gov/heatisland/resources/pdf/BasicsCompendium.pdf

[22] G. L. Authority, "London's Urban Heat Island:A Summary for Decision Makers," London, UK2006.

[23] S. A. H. Saleh, "<IMPACT OF URBAN EXPANSION ON SURFACE TEMPERATURE IN Baghdad.pdf>," Journal of Al-Nahrain University, vol. 13, pp. 48-59, March, 20102010.

[24] C. Population. (2013, July). Governorates \& Regions. Available: http://www.citypopulation.de/

[25] QGIS. (2016, 20-5-2015). Download QGIS for your platform. Available: http://www2.qgis.org/en/site/forusers/download.html

[26] Z.-L. Li, B.-H. Tang, H. Wu, H. Ren, G. Yan, Z. Wan, et al., "Satellite-derived land surface temperature: Current status and perspectives," Remote Sensing of Environment, vol. 131, pp. 14-37, 4/15/ 2013.

[27] USGS. (2016, 20-3-2015). Earth Explorer. Available: http://earthexplorer.usgs.gov/

[28] A. R. As-syakur, I. W. S. Adnyana, I. W. Arthana, and I. W. Nuarsa, "Enhanced Built-Up and Bareness Index (EBBI) for Mapping Built-Up and Bare Land in an Urban Area," Remote Sensing, vol. 4, pp. $2957-$ $2970,2012$.

[29] X.-L. Chen, H.-M. Zhao, P.-X. Li, and Z.-Y. Yin, "Remote sensing image-based analysis of the relationship between urban heat island and land use/cover changes," Remote Sensing of Environment, vol. 104, pp. 133-146, 9/30/ 2006.

[30] W. Y. Takeuchi, Y. (2004). Development of normalized vegetation,

soil and water indices derived from

satellite remote sensing data. Available: http://webmodis.iis.u-tokyo.ac.jp/PADDY/pdf/acrs2004_2_presen.pdf

[31] USGS. (2016, 8-6-2015). USGS Global Visualization Viewer. Available: http://glovis.usgs.gov/

[32] J. Khan and T. Powell, "Land Use in the UK."

[33] NERC. (2011). Land Cover Map 2007. Available: http://www.ceh.ac.uk/landcovermap2007.html 
[34] R. Bouhennache, T. Bouden, A. Taleb, and A. Chaddad, "Extraction of Urban Land Features from TM Landsat Image Using the Land Features Index and Tasseled Cap Transformation," Extraction, vol. 1, p. 33037.

[35] I. Ogashawara and V. d. S. B. Bastos, "A quantitative approach for analyzing the relationship between urban heat islands and land cover," Remote Sensing, vol. 4, pp. 3596-3618, 2012.

[36] Z. Du, W. Li, D. Zhou, L. Tian, F. Ling, H. Wang, et al., "Analysis of Landsat-8 OLI imagery for land surface water mapping," Remote Sensing Letters, vol. 5, pp. 672-681, 2014/07/03 2014.

[37] J. R. Jensen, Remote Sensing of the Environment: An Earth Resource Perspective: Pearson Prentice Hall, 2007.

[38] S. A. H. Saleh1, "REMOTE SENSING AND GIS TECHNIQUES FOR URBAN GROWTH MONITORING OF BASARAH CITY," International Journal of Remote Sensing and Earth Sciences, vol. 7, pp. 73-83, 2010.

[39] F. Rossi, B. Castellani, A. Presciutti, E. Morini, E. Anderini, M. Filipponi, et al., "Experimental evaluation of urban heat island mitigation potential of retro-reflective pavement in urban canyons," Energy and Buildings, vol. 126, pp. 340-352, 8/15/ 2016. 